\title{
The Genus Metschnikowia in Enology
}

\author{
Javier Vicente ${ }^{1}{ }^{\circledR}$, Javier Ruiz ${ }^{1}$, Ignacio Belda ${ }^{1}$, Iván Benito-Vázquez ${ }^{1}$, Domingo Marquina ${ }^{1}$, \\ Fernando Calderón ${ }^{2}$, Antonio Santos ${ }^{1}$ (D) and Santiago Benito ${ }^{2, *(D)}$ \\ 1 Unit of Microbiology, Department of Genetics, Physiology and Microbiology, Biology Faculty, Complutense \\ University of Madrid, 28040 Madrid, Spain; javievic@ucm.es (J.V.); javiru02@ucm.es (J.R.); \\ ignaciobelda@ucm.es (I.B.); ivbenito@ucm.es (I.B.-V.); dommarq@bio.ucm.es (D.M.); ansantos@ucm.es (A.S.) \\ 2 Department of Chemistry and Food Technology, Polytechnic University of Madrid, Ciudad Universitaria \\ S/N, 28040 Madrid, Spain; fernando.calderon@upm.es \\ * Correspondence: santiago.benito@upm.es; Tel.: +34-913363984
}

Received: 31 May 2020; Accepted: 4 July 2020; Published: 13 July 2020

\begin{abstract}
Over the last decade, several non-Saccharomyces species have been used as an alternative yeast for producing wines with sensorial properties that are distinctive in comparison to those produced using only Saccharomyces cerevisiae as the classical inoculum. Among the non-Saccharomyces wine yeasts, Metschnikowia is one of the most investigated genera due to its widespread occurrence and its impact in winemaking, and it has been found in grapevine phyllospheres, fruit flies, grapes, and wine fermentations as being part of the resident microbiota of wineries and wine-making equipment. The versatility that allows some Metschnikowia species to be used for winemaking relies on an ability to grow in combination with other yeast species, such as S. cerevisiae, during the first stages of wine fermentation, thereby modulating the synthesis of secondary metabolites during fermentation in order to improve the sensory profile of the wine. Metschnikowia exerts a moderate fermentation power, some interesting enzymatic activities involving aromatic and color precursors, and potential antimicrobial activity against spoilage yeasts and fungi, resulting in this yeast being considered an interesting tool for use in the improvement of wine quality. The abovementioned properties have mostly been determined from studies on Metschnikowia pulcherrima wine strains. However, M. fructicola and M. viticola have also recently been studied for winemaking purposes.
\end{abstract}

Keywords: non-Saccharomyces; Metschnikowia; M. pulcherrima; M. viticola; M. fructicola; wine flavor

\section{Introduction}

In spontaneous wine fermentation, yeast species other than Saccharomyces cerevisiae, such as Hanseniaspora, Pichia, Torulaspora, Lachancea, or Metschnikowia species, govern the initial phase of alcoholic fermentation, thereby influencing the final sensory character of wines, as previously reviewed [1]. The presence of these yeasts is mainly limited to the first half of the alcoholic fermentation process, since they are quickly replaced by S. cerevisiae, which has higher fermentative potential.

S. cerevisiae starts to predominate when the level of alcohol begins to be a selective factor, as only a few fermentative yeasts, i.e., those showing high ethanol resistance, can cope. However, with the industrial use of active dry yeasts (ADYs) comprising selected S. cerevisiae strains as a widespread and useful tool for reducing industrial risks in winemaking, the contribution of these first-phase non-Saccharomyces species tend to be nullified in the majority of industrialized wineries.

During the last decade, specific strains of non-Saccharomyces species have been reported as being able to improve different technological and sensory parameters of wine (e.g., aroma complexity, color stability, acidity, polysaccharide production, and clarification) [2,3]. Their use seems to be focused on reducing the ethanol content of wines and increasing the release of mannoproteins together with the impact of hydrolytic enzymes in extracting color and aroma precursors from grapes $[4,5]$. 
On the contrary, some of the challenges linked with the use of non-Saccharomyces species in modern winemaking are related to their low fermentation power and low tolerance to $\mathrm{SO}_{2}$, along with difficulties in upscaling production for ADYs. In addition, the use of some non-Saccharomyces species has been reported to result in negative consequences for wines for reasons that are related to their sluggish fermentation or excessive production of acetic acid, ethyl acetate, acetaldehyde, or acetoin [6].

Among the non-Saccharomyces yeasts, Metschnikowia is a genus of ascomycetous yeasts characterized by cells containing a large oil drop with multilateral budding as well as the formation of large needle-shaped spores in elongated asci. Currently, the number of described Metschnikowia species exceeds $80[7,8]$, with M. pulcherrima, M. fructicola, and M. viticola most commonly found in wine-related environments [9-11].

M. pulcherrima, which is ovoidal in shape, usually reproduces by budding, although pseudohyphal growth can be observed under anaerobic conditions. Over the years, M. pulcherrima has come to be known by a multitude of different names due to changes in its classification based on classical methods on yeast taxonomy (Asporomyces uvae, Candida pulcherrima, Castellania castellanii, Cryptococcus castellanii, Eutorula pulcherrima, Monilia castellanii, Rhodotorula pulcherrima, Saccharomyces pulcherrimus, Torula pulcherrima, Torulopsis pulcherrima, Torulopsis burgeffiana, Torulopsis dattila, etc.) [8].

M. pulcherrima shows a low to moderate fermentative power, as is the case with most non-Saccharomyces species that are present in grapes. This species is not able to tolerate ethanol concentrations over $4-5 \%(v / v)$, so it naturally disappears during alcoholic fermentation when this concentration of ethanol is exceeded. Furthermore, although M. pulcherrima shows moderate resistance to $\mathrm{SO}_{2}$, higher than for some other non-Saccharomyces wine species, this tolerance is always lower than that observed for Saccharomyces wine strains $[12,13]$. For these reasons, M. pulcherrima should be used in mixed fermentations with a yeast that exhibits a higher fermentative power, such as S. cerevisiae, which will then be the species responsible for finishing alcoholic fermentation [14]. Accordingly, dehydrated yeast manufacturers recommend the use of selected M. pulcherrima strains in sequential inoculation with $S$. cerevisiae in order to maximize its effects on determined characteristics in the final product, as is usually done with other commercial non-Saccharomyces species such as T. delbrueckii, L. thermotolerans, or Pichia kluyveri [15].

In this review, the interesting antimicrobial properties of M. pulcherrima are also considered in the context of winemaking. It has been reported that $M$. pulcherrima shows strong biocontrol activity against various yeast genera that are considered detrimental in enology (Brettanomyces/Dekkera, Hanseniaspora, and Pichia) and several filamentous fungi that cause grape spoilage (Penicillium sp., Aspergillus sp., and Fusarium sp.), while having a low to null effect on $S$. cerevisiae performance. The production of the iron sequestering brown-red pigment pulcherrimin is responsible for this observed inhibition $[16,17]$. In addition, the presence of killer toxins cannot be ruled out as their production has been described for other Metschnikowia species [18].

Although it is widely assumed that M. pulcherrima may exert a positive impact in many wine quality parameters, several authors have reported significant strain-dependent variability [19]. This review discusses properties that have already been studied in different strains of M. pulcherrima that may positively impact wine quality [20]. Additionally, we discuss some key operational concepts for enhancing positive attributes through the use of an M. pulcherrima inoculum in wine fermentation.

In the last decade, $M$. pulcherrima has been studied in detail in terms of its relation to the production of wine [21]. However, other species of the same genus, such as M. viticola [22] and M. fructicola [23], are also receiving some scientific attention, and development of their application within the wine industry has already begun.

It is well known that non-Saccharomyces yeasts are responsible for the production of a great variety of enzymes that contribute to the organoleptic characteristics of wines. Among them, the Metschnikowia genus stands out because of its ability to produce hydrolytic enzymes (glycosidases, proteases, and pectinases), which may directly impact the sensorial and technological properties of wine [24]. 
In summary, the Metschnikowia genus possesses different characteristics that could be utilized in different industrial or agricultural processes. Taking advantage of those characteristics, different strains have been selected and commercialized for different uses (Table 1).

Table 1. Commercial products based on different Metschnikowia species, company, and recommended use.

\begin{tabular}{|c|c|c|c|}
\hline Species & Products & Company & Applications \\
\hline M. pulcherrima & Flavia $^{\mathrm{TM}}$ MP346 & Lallemand & $\begin{array}{l}\text { In white wines, it increases the varietal } \\
\text { thiols and improves the acidity }\end{array}$ \\
\hline \multirow{3}{*}{ M. fructicola } & Excellence $^{\mathrm{TM}}$ & Bio-Nature & $\begin{array}{l}\text { To control the indigenous flora present in } \\
\text { grape and in must it enables a } \\
\text { controlled fermentation }\end{array}$ \\
\hline & Gaїа & Lallemand & $\begin{array}{l}\text { To reduce the prefermentation sulfiting. } \\
\text { To facilitate the implantation of the } \\
\text { S. cerevisiae selected strain }\end{array}$ \\
\hline & Noliti & Koppert & $\begin{array}{l}\text { Tool for preventing the decay in fruit } \\
\text { caused by Botrytis spp. and Monilinia } \\
\text { spp., which seriously affect the quality of } \\
\text { harvested grapes }\end{array}$ \\
\hline
\end{tabular}

Thus, the aim of the present work is to compile and synthetize the results and conclusions obtained from different research groups during the last few years. To facilitate understanding and management, different enological traits of M. pulcherrima have been summarized (Table 2). 
Table 2. Summary of final values of several wine quality parameters obtained in different studies that performed combined fermentations between M. pulcherrima and S. cerevisiae (Mp Sc) and control fermentations with S. cerevisiae (Sc).

\begin{tabular}{|c|c|c|c|c|c|c|c|c|c|c|c|c|c|c|}
\hline \multirow[t]{2}{*}{ Metabolite } & \multicolumn{2}{|c|}{ Comitini et al., 2011 [19] } & \multicolumn{2}{|c|}{$\begin{array}{c}\text { González-Royo et al., } 2014 \\
\text { [25] }\end{array}$} & \multicolumn{2}{|c|}{ Benito et al., 2015 [26] } & \multicolumn{2}{|c|}{ Chen et al., 2018 [27] } & \multicolumn{2}{|c|}{$\begin{array}{c}\text { Escribano-Viana et al., } \\
2018[28]\end{array}$} & \multicolumn{2}{|c|}{ Ruiz et al., 2018 [21] } & \multicolumn{2}{|c|}{ Dutraive et al, 2019 [29] } \\
\hline & $\mathrm{Mp} \ldots \mathrm{Sc}$ & Sc & $\mathrm{Mp} \ldots \mathrm{Sc}$ & Sc & $\mathrm{Mp} \ldots \mathrm{Sc}$ & Sc & $\mathrm{Mp} \ldots \mathrm{Sc}$ & Sc & $\mathrm{Mp} \ldots \mathrm{Sc}$ & Sc & $\mathrm{Mp} \ldots \mathrm{Sc}$ & Sc & $\mathrm{Mp} \ldots \mathrm{Sc}$ & Sc \\
\hline $\begin{array}{c}\text { Ethanol }(\% \\
v / v)\end{array}$ & $13.87 \pm 0.01$ & $13.93 \pm 0.06$ & $10.6 \pm 0.3$ & $10.70 \pm 0.10$ & $13.61 \pm 0.02$ & $13.80 \pm 0.01$ & $12.60 \pm 0.00$ & $12.50 \pm 0.06$ & $14.15 \pm 0.05$ & 14.3 & $12.38 \pm 0.38$ & $13.00 \pm 0.01$ & $12.98 \pm 0.35$ & $13.20 \pm 0.19$ \\
\hline $\begin{array}{c}\text { Residual } \\
\text { sugar }(g / L)\end{array}$ & 1 & I & I & I & $4.20 \pm 0.17$ & $4.65 \pm 0.35$ & $2.20 \pm 0.30$ & $2.30 \pm 0.32$ & I & I & $3.45 \pm 0.36$ & $3.27 \pm 0.05$ & $4.50 \pm 0.30$ & $4.40 \pm 0.25$ \\
\hline $\begin{array}{l}\text { Lactic acid } \\
(\mathrm{g} / \mathrm{L})\end{array}$ & 1 & 1 & l & l & $0.00 \pm 0.00$ & $0.00 \pm 0.00$ & $0.00 \pm 0.00$ & $0.00 \pm 0.00$ & l & l & $0.14 \pm 0.03$ & $0.10 \pm 0.01$ & $0.21 \pm 0.01$ & $0.21 \pm 0.01$ \\
\hline $\begin{array}{l}\text { Malic acid } \\
(\mathrm{g} / \mathrm{L})\end{array}$ & 1 & 1 & l & l & / & / & $1.7 \pm 0.15$ & $2.00 \pm 0.11$ & $1.87 \pm 0.11$ & 2.46 & $1.62 \pm 0.06$ & $1.83 \pm 0.06$ & $2.10 \pm 0.01$ & $2.28 \pm 0.00$ \\
\hline $\begin{array}{c}\text { Acetic acid } \\
(\mathrm{g} / \mathrm{L})\end{array}$ & $0.30 \pm 0.04$ & $0.46 \pm 0.01$ & $0.21 \pm 0.02$ & $0.18 \pm 0.01$ & $0.37 \pm 0.02$ & $0.38 \pm 0.01$ & $0.17 \pm 0.05$ & $0.19 \pm 0.03$ & $0.11 \pm 0.01$ & 0.16 & $0.36 \pm 0.03$ & $0.39 \pm 0.01$ & $0.30 \pm 0.03$ & $0.25 \pm 0.03$ \\
\hline$\Sigma$ acids $(\mathrm{g} / \mathrm{L})$ & $6.33 \pm 0.27$ & $7.05 \pm 0.04$ & l & l & l & l & $5.20 \pm 0.10$ & $5.60 \pm 0.12$ & l & l & l & l & l & l \\
\hline $\begin{array}{c}\text { Glycerol } \\
(\mathrm{g} / \mathrm{L})\end{array}$ & $6.53 \pm 0.27$ & $6.23 \pm 0.54$ & $5.3 \pm 0.6$ & $4.70 \pm 0.01$ & $6.12 \pm 0.04$ & $5.88 \pm 0.02$ & & /I & $8.27 \pm 0.11$ & 7.55 & & & $7.0 \pm 0.05$ & $5.8 \pm 0.04$ \\
\hline $\begin{array}{l}\text { Acetaldehyde } \\
(\mathrm{mg} / \mathrm{L})\end{array}$ & $41.84 \pm 3.07$ & $30.48 \pm 1.97$ & $1.57 \pm 0.14$ & $2.33 \pm 1.11$ & $33.00 \pm 1.00$ & $53.50 \pm 2.12$ & $7.94 \pm 0.96$ & $10.11 \pm 1.20$ & I & / & $39.00 \pm 2.11$ & $54.67 \pm 5.13$ & I & 1 \\
\hline $\begin{array}{c}\text { 2-phenyl-ethano } \\
(\mathrm{mg} / \mathrm{L})\end{array}$ & $\mathrm{ol}_{9.49 \pm 1.00}$ & $\begin{array}{c}12.07 \pm \\
0.403\end{array}$ & l & / & $19.10 \pm 0.3$ & 1.44 & $27.82 \pm 1.80$ & $\begin{array}{c}41.16 \pm \\
27.25\end{array}$ & $64.99 \pm 1.27$ & 47.8 & $21.92 \pm 0.09$ & $17.81 \pm 1.75$ & $18.00 \pm 0.60$ & $13.74 \pm 1.20$ \\
\hline $\begin{array}{c}\text { 3-methyl-butano } \\
(\mathrm{mg} / \mathrm{L})\end{array}$ & ol & I & $231.0 \pm 23.8$ & $\begin{array}{c}178.60 \pm \\
11.30\end{array}$ & $14.63 \pm 0.74$ & $16.54 \pm 2.10$ & I & I & I & I & $96.45 \pm 5.34$ & $\begin{array}{c}163.85 \pm \\
5.20\end{array}$ & I & I \\
\hline $\begin{array}{c}\text { Hexanol } \\
(\mathrm{mg} / \mathrm{L})\end{array}$ & $0.40 \pm 0.08$ & $0.38 \pm 0.05$ & $0.92 \pm 0.05$ & $0.92 \pm 0.06$ & $0.72 \pm 0.16$ & $1.05 \pm 0.01$ & $4.00 \pm 0.09$ & $3.74 \pm 0.07$ & $1.71 \pm 0.21$ & 1.82 & $0.60 \pm 0.03$ & $1.93 \pm 0.75$ & $1.28 \pm 0.07$ & $1.13 \pm 0.04$ \\
\hline $\begin{array}{c}\sum \text { higher } \\
\text { alcohols } \\
(\mathrm{mg} / \mathrm{L}) \\
\text { Ethyl }\end{array}$ & $\begin{array}{c}290.23 \pm \\
73.97\end{array}$ & $\begin{array}{c}244.09 \pm \\
42.51\end{array}$ & $311.7 \pm 22.6$ & $\begin{array}{c}257.40 \pm \\
16.80\end{array}$ & $\begin{array}{c}161.43 \pm \\
6.24\end{array}$ & $\begin{array}{c}208.59 \pm \\
17.83\end{array}$ & I & I & $\begin{array}{c}153.43 \pm \\
6.36\end{array}$ & 1.82 & $\begin{array}{c}159.19 \pm \\
10.00\end{array}$ & $\begin{array}{c}236.55 \pm \\
12.4\end{array}$ & $\begin{array}{c}232.23 \pm \\
11.84\end{array}$ & $\begin{array}{c}203.48 \pm \\
9.95\end{array}$ \\
\hline $\begin{array}{l}\text { Ethyl } \\
\text { butanoate } \\
\text { (mg/L) } \\
\text { Ethyl }\end{array}$ & 1 & I & I & I & $0.56 \pm 0.13$ & $\begin{array}{c}558.92 \pm \\
19.75\end{array}$ & 1 & 1 & I & I & $0.18 \pm 0.01$ & $0.15 \pm 0.03$ & $0.33 \pm 0.02$ & $0.43 \pm 0.03$ \\
\hline $\begin{array}{c}\text { hexanoate } \\
\text { (mg/L) } \\
\text { Ethyl }\end{array}$ & $0.14 \pm 0.02$ & $0.185 \pm 0.02$ & $0.68 \pm 0.06$ & $1.03 \pm 0.22$ & $1.33 \pm 0.13$ & $1.21 \pm 0.03$ & 1 & 1 & I & I & $0.57 \pm 0.02$ & $053 \pm 0.01$ & $1.99 \pm 0.05$ & $1.88 \pm 0.07$ \\
\hline $\begin{array}{c}\text { decanoate } \\
(\mathrm{mg} / \mathrm{L})\end{array}$ & $0.15 \pm 0.01$ & $0.38 \pm 0.01$ & $0.14 \pm 0.01$ & $0.39 \pm 0.11$ & $0.68 \pm 0.07$ & $0.65 \pm 0.02$ & I & I & I & I & $0.27 \pm 0.01$ & $0.20 \pm 0.02$ & $0.55 \pm 0.09$ & $0.44 \pm 0.06$ \\
\hline $\begin{array}{c}\text { Ethyl lactate } \\
(\mathrm{mg} / \mathrm{L})\end{array}$ & $3.71 \pm 0.73$ & $7.66 \pm 2.34$ & $6.78 \pm 0.23$ & $8.01 \pm 0.71$ & $8.57 \pm 0.19$ & $9.76 \pm 0.15$ & $7.37 \pm 1.19$ & $10.06 \pm 2.05$ & $2.57 \pm 0.11$ & 0.48 & / & I & 1 & I \\
\hline $\begin{array}{c}\text { Ethyl acetate } \\
(\mathrm{mg} / \mathrm{L}) \\
\text { Isoamyl }\end{array}$ & $30.42 \pm 2.18$ & $28.44 \pm 7.69$ & $19.6 \pm 0.4$ & $24.40 \pm 2.50$ & $57.34 \pm 3.72$ & $75.48 \pm 9.99$ & $\begin{array}{c}51.20 \pm \\
12.78\end{array}$ & $31.50 \pm 1.23$ & I & I & $37.64 \pm 1.36$ & $0.11 \pm 0.03$ & $\begin{array}{c}115.53 \pm \\
6.80\end{array}$ & $\begin{array}{c}159.18 \pm \\
7.20\end{array}$ \\
\hline $\begin{array}{l}\text { acetate } \\
(\mathrm{mg} / \mathrm{L})\end{array}$ & $0.22 \pm 0.01$ & $0.26 \pm 0.01$ & $0.53 \pm 0.02$ & $0.46 \pm 0.04$ & $2.44 \pm 0.10$ & $3.67 \pm 0.24$ & $8.02 \pm 3.35$ & $6.61 \pm 0.92$ & $1.99 \pm 0.30$ & 2.13 & $1.15 \pm 0.00$ & $1.33 \pm 0.25$ & I & I \\
\hline
\end{tabular}


Table 2. Cont.

\begin{tabular}{|c|c|c|c|c|c|c|c|c|c|c|c|c|c|c|}
\hline \multirow[t]{2}{*}{ Metabolite } & \multicolumn{2}{|c|}{ Comitini et al., 2011 [19] } & \multicolumn{2}{|c|}{$\begin{array}{c}\text { González-Royo et al., } 2014 \\
\text { [25] }\end{array}$} & \multicolumn{2}{|c|}{ Benito et al., 2015 [26] } & \multicolumn{2}{|c|}{ Chen et al., 2018 [27] } & \multicolumn{2}{|c|}{$\begin{array}{c}\text { Escribano-Viana et al., } \\
2018[28]\end{array}$} & \multicolumn{2}{|c|}{ Ruiz et al., 2018 [21] } & \multicolumn{2}{|c|}{ Dutraive et al, 2019 [29] } \\
\hline & $\mathrm{Mp} \ldots \mathrm{Sc}$ & Sc & $\mathrm{Mp} \ldots \mathrm{Sc}$ & Sc & $\mathbf{M p} \ldots \mathrm{Sc}$ & Sc & $\mathrm{Mp} \ldots \mathrm{Sc}$ & Sc & $\mathbf{M p} \ldots \mathrm{Sc}$ & Sc & $\mathrm{Mp} \ldots \mathrm{Sc}$ & Sc & $\mathrm{Mp} \ldots \mathrm{Sc}$ & Sc \\
\hline $\begin{array}{l}\text { 2-phenyl-ethyl } \\
\text { acetate } \\
(\mathrm{mg} / \mathrm{L})\end{array}$ & I & l & $1.82 \pm 0.20$ & $2.37 \pm 0.16$ & $0.83 \pm 0.06$ & $0.96 \pm 0.02$ & $5.42 \pm 0.40$ & $6.60 \pm 0.40$ & $0.16 \pm 0.01$ & 0.13 & $0.34 \pm 0.04$ & $0.21 \pm 0.03$ & $0.36 \pm 0.01$ & $0.43 \pm 0.09$ \\
\hline $\begin{array}{c}\Sigma \text { acetates } \\
(\mathrm{mg} / \mathrm{L})\end{array}$ & l & l & I & I & $61.19 \pm 3.6$ & $80.73 \pm 9.66$ & I & I & $2.65 \pm 0.40$ & 2.26 & I & l & $\begin{array}{c}120.29 \pm \\
6.81\end{array}$ & $\begin{array}{c}164.23 \pm \\
7.36\end{array}$ \\
\hline $\begin{array}{c}\sum \text { esters } \\
(\mathrm{mg} / \mathrm{L})\end{array}$ & I & l & l & / & $73.88 \pm 3.28$ & $94.33 \pm 8.93$ & / & / & I & I & $41.26 \pm 1.49$ & $\begin{array}{c}45.23 \pm \\
11.23\end{array}$ & $\begin{array}{c}124.84 \pm \\
6.79\end{array}$ & $\begin{array}{c}168.45 \pm \\
7.37\end{array}$ \\
\hline $\begin{array}{l}\text { Hexanoic } \\
\text { acid }(\mathrm{mg} / \mathrm{L})\end{array}$ & $1.95 \pm 0.07$ & $0.80 \pm 0.01$ & $3.75 \pm 0.16$ & $4.62 \pm 0.35$ & $12.82 \pm 0.26$ & $11.98 \pm 0.97$ & I & I & I & I & $7.09 \pm 0.12$ & $7.04 \pm 0.19$ & $11.38 \pm 0.14$ & $11.13 \pm 0.30$ \\
\hline $\begin{array}{l}\text { Octanoic } \\
\text { acid }(\mathrm{mg} / \mathrm{L})\end{array}$ & $1.02 \pm 0.04$ & $1.05 \pm 0.01$ & $15.86 \pm 0.70$ & $20.11 \pm 2.57$ & $6.55 \pm 0.09$ & $6.72 \pm 0.18$ & I & I & $1.87 \pm 0.23$ & 2.57 & $5.55 \pm 0.18$ & $4.84 \pm 0.35$ & $11.56 \pm 0.75$ & $11.99 \pm 0.20$ \\
\hline $\begin{array}{c}\text { Decanoic } \\
\text { acid }(\mathrm{mg} / \mathrm{L})\end{array}$ & $0.81 \pm 0.04$ & $0.23 \pm 0.04$ & $0.3 \pm 0.0$ & $0.6 \pm 0.00$ & $2.92 \pm 0.13$ & $3.1 \pm 0.06$ & / & / & / & l & $1.09 \pm 0.06$ & $0.68 \pm 0.11$ & $4.23 \pm 0.18$ & $4.21 \pm 0.14$ \\
\hline
\end{tabular}




\section{The Genus Metschnikowia: Scientific and Enological Contexts}

According to the NCBI taxonomy browser, the family Metschnikowiaceae currently comprises five different genera, namely, Aciculoconidium, Clavispora, Kodamaea, Metschnikowia, and Nectaromyces. The genus Metschnikowia has been defined as a clade containing 81 different species [30,31]. Most Metschnikowia species are not ecologically widespread, but they show a high degree of specialization [32,33]. Members of the M. pulcherrima clade appear to be primarily associated with fruit-feeding insects. In vineyard- and wine-related environments, the species M. pulcherrima, M. fructicola, and M. viticola have been reported [10]. In this work, M. viticola was apparently easy to differentiate from M. pulcherrima and M. fructicola from both a phylogenetic and phenotypic point of view. However, M. pulcherrima and M. fructicola are difficult to separate when examining wine-related traits or by sequencing generally accepted ribosomal DNA markers (ITS or 26S rDNA partial sequencing) [34]. Fortunately, they can be differentiated by comparing the nucleotide sequence of the EF2 (elongation factor 2) marker [32], which shows around 9\% sequence divergence between these species.

Figure 1A shows a scheme of the phylogenetic relationship (based on 26S rDNA sequences) between the Metschnikowia species, S. cerevisiae, and two of the main other non-Saccharomyces yeasts commonly commercialized in wine industry (L. thermotolerans and T. delbrueckii). As can be deduced from their functional traits (fermentation capacity, ethanol, and $\mathrm{SO}_{2}$ tolerance), T. delbrueckii is closely related with S. cerevisiae in comparison with the L. thermotolerans and Metschnikowia yeasts, which contrarily show a notably a lower fermentation capacity and lower ethanol and $\mathrm{SO}_{2}$ tolerance than the S. cerevisiae and T. delbrueckii species. However, Figure 1B shows that the Metschnikowia and Lachancea species have a higher occurrence rate than the Torulaspora species in grape and wine samples. In fact, the Metschnikowia species appeared in grape and grape must samples with abundance patterns like those of Saccharomyces species.

A

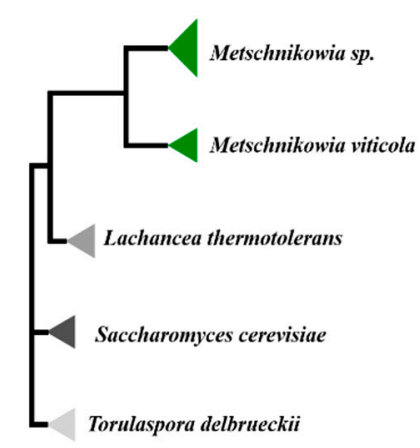

B

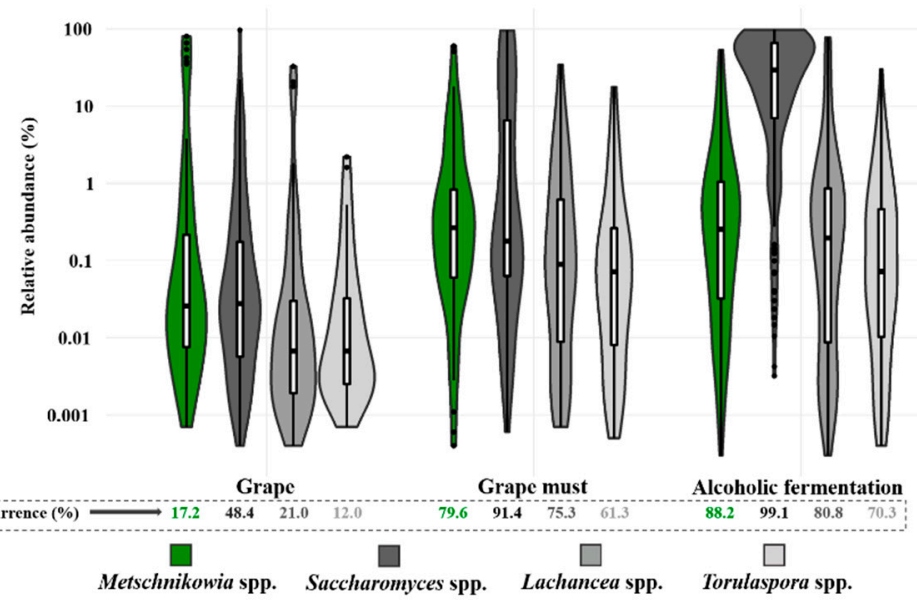

Figure 1. (A) Scheme of the phylogenetic relationship between Metschnikowia sp. (including isolates of M. pulcherrima and M. fructicola species), M. viticola, Saccharomyces cerevisiae, Torulaspora delbrueckii, and Lachancea thermotolerans, using $26 \mathrm{~S}$ rRNA sequences. (B) Occurrence rates and relative abundance values at different winemaking stages for the above-mentioned yeast genera (personal communication from A. Acedo; values estimated from a large-scale NGS amplicon-based survey).

In examining the scientific interest in the abovementioned wine-relevant non-Saccharomyces species (using a PubMed ${ }^{\circledR}$ search with the following search strategy: "(Genus_name) AND wine", we can highlight that in terms of wine-related studies, the first mention of Torulaspora yeasts was in 1973 (though such reports only started to appear regularly since 1987), with reports of Metschnikowia appearing in 1999 and, more recently, Lachancea (including searches for Kluyveromyces thermotolerans, 
by which the currently named L. thermotolerans was formerly known) in 2001 (Figure 2). However, in 2019, Metschnikowia was mentioned in 22 wine-related scientific works and the Torulaspora and Lachancea yeasts in 19 and 18 works, respectively. Thus, in last few years, the increasing incidence of Metschnikowia yeasts occurring in wine-related environments and their increasing number of potential uses in improving wine quality mirror the greater attention from researchers.
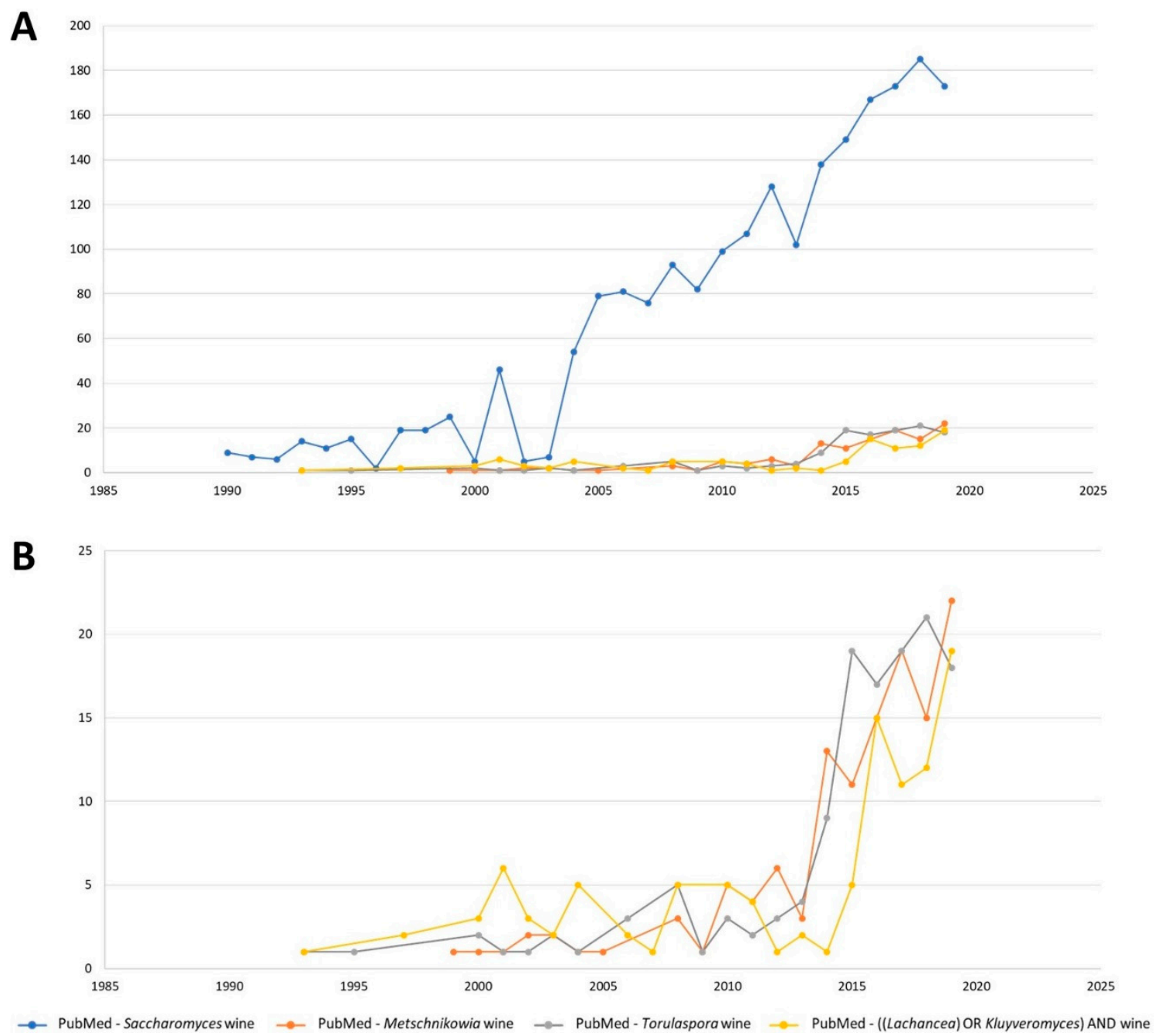

Figure 2. Graphical representation of the number of publications by year (1990 to 2020) related to a yeast genus and wine search in PubMed. (A) Results looking for Saccharomyces, Metschnikowia, Torulaspora, and Lachancea (or Kluyveromyces). (B) Detail of the results looking for Metschnikowia, Torulaspora, and Lachancea (or Kluyveromyces).

The complete genome sequences of different strains of $M$. pulcherrima and $M$. fructicola, isolated from different environments (soil, insects, grapes, etc.), are already available [35-38] and are useful in guiding future research efforts on the basic and applied aspects of Metschnikowia. These resources open new possibilities for understanding the transcriptional regulation of the various Metschnikowia species [35] as a necessary step for their wider and more controlled use in industrial and in-field operations.

\section{Fermentation Parameters}

\subsection{Fermentation Capacity}

Ethanol production under winemaking conditions is directly linked to the fermentation capacity of the utilized yeast and its tolerance to ethanol, which is low in the case of Metschnikowia. Some 
strategies for ethanol reduction in wine are based on using non-Saccharomyces yeasts, due to their low fermentative yield, or due to the possibility of forcing a Crabtree-negative effect, thereby consuming sugars by respiration [39]. The remaining sugar that it is not converted into ethanol may be transformed into other compounds, such as glycerol or acids [26]. Nevertheless, in some cases, the residual sugar present at the end of the fermentative process is extremely high (up to $150 \mathrm{~g} / \mathrm{L}$ ) [40].

The fermentative capacity of $M$. pulcherrima is limited under single-inoculation fermentation conditions. Most studies have reported M. pulcherrima as producing up to 4.5\% (v/v) ethanol [41]. This moderate fermentation power makes it impossible to use a single Metschnikowia inoculum for wine fermentation, or even for lower ethanol beverages such as beer. However, some strains of M. pulcherrima are able to produce around $9 \%(v / v)$ ethanol, though this process takes 180 days and also consumes almost all the sugar [42]. This is the reason why M. pulcherrima is preferred for improving quality parameters such as the aroma in sequential fermentations where it is combined with more fermentative yeasts such as S. cerevisiae.

Despite its resistance to all $S$. cerevisiae killer toxins and the absence of any antagonistic interactions between M. pulcherrima and S. cerevisiae [40,43]; when inoculated together at equal cell density, the M. pulcherrima population decreases rapidly due to its low ethanol resistance [26]. The use of sequential inoculation strategies could solve this problem derived from the low ethanol resistance of M. pulcherrima.

The effect of the sequential inoculation depends on the initial density of the S. cerevisiae population used in the second inoculation [19], the specific strains that are used, and the combinations [44]. Several studies have shown slight differences, with an observed decrease in ethanol production ranging from $1.39 \%$ to $0.2 \%(v / v)$ compared to regular fermentations with only S. cerevisiae $[19,26,41,45,46]$. The use of the sequential fermentation modality usually delays the alcoholic fermentation time by around four days in comparison to the $S$. cerevisiae controls [47].

The fermentation power of M. pulcherrima is strain- and culture condition-dependent. The results obtained by some research groups regarding the initial must composition, $\mathrm{pH}$, diammonium phosphate, sulfur dioxide, and temperature indicate the importance of performing studies in order to optimize the parameters that have a major influence in the metabolism of M. pulcherrima $[40,43]$.

In addition to M. pulcherrima, some other species of Metschnikowia have been studied in fermentation. Wines fermented with S. cerevisiae in combination with M. viticola (and even M. fructicola) usually have residual sugar and low ethanol content (10-11.9\% ethanol) [22].

\subsection{Glycerol}

Glycerol plays an important role in wine properties because it is associated with different characteristics, such as flavor persistence and oiliness [48]. The use of Metschnikowia increases the final concentration of glycerol in wines. Recent works have revealed that the increase in glycerol during sequential inoculation ranges from 4 to $20 \%$ [26,29], or even up to more than $40 \%$ [41]. The presence of competitors may influence glycerol production, which is higher when the cellular concentration of S. cerevisiae is lower [19].

The physicochemical conditions are also decisive in the production of glycerol. The addition of $60 \mathrm{mg} / \mathrm{L}$ sulfur dioxide to must decreased the production of glycerol by one-third [43], which could be explained by the low resistance to the oxide [19].

\subsection{Nitrogen Metabolism}

The consumption of different nitrogen assimilable sources (NAS) by M. pulcherrima was assayed under in vitro conditions. These studies, which examined both single and mixed fermentations employing M. pulcherrima and S. cerevisiae, reported that at the end of the fermentation a significant amount (up to $40 \%$ ) of the studied NAS had not been consumed when single cultures of the non-Saccharomyces species were used, whereas Saccharomyces consumed all the nitrogen sources present 
in the media, including in mixed cultures [49]. In a recent study, M. pulcherrima is the least influenced yeast species by the must nitrogen composition [50].

During sequential fermentation with M. pulcherrima and S. cerevisiae, adequate management of yeast nutrition is essential, especially regarding the nitrogen source. The addition of nitrogen at the moment of $S$. cerevisiae inoculation is recommended for facilitating the completion of the fermentative process [51]. M. pucherrima sequential fermentations seems to increase the final amino acid concentration in wine. The higher increments of amino acids are because of increases in isoleucine, serine, and phenylalanine. Those amino acids doubled its concentration compared to the S. cerevisiae control. Threonine was the only amino acid that decreased [26].

The use of M. pulcherrima in aging on lees also triggers an increase in the final amino acid concentration of wines. During aging, the use of M. pulcherrima lees in combination with S. cerevisiae increases the final concentration of amino acids compared with the single use of S. cerevisiae, especially in the amount of histidine and tryptophan (63\%). On the contrary, threonine is highlighted because it is the only amino acid that was observed to decrease [52].

\subsection{Total Acidity}

The inclusion of Metschnikowia in must fermentation seems to be associated with slight losses in the total acidity of the final wine as reflected by an increase in $\mathrm{pH}$. The loss in total acidity that affects $\mathrm{pH}$ may involve microbial, protein, or color instability.

Variable results have been encountered when considering single S. cerevisiae fermentations compared to sequential fermentations using M. pulcherrima and S. cerevisiae, where the reduction in total acidity in sequential fermentations has been observed to be both statistically nonsignificant (e.g., from pH 3.39 to 3.40) [26,27] and significant (e.g., from pH 3.40 to 4.20) [19,29]. Nevertheless, in some cases, higher final levels in titratable acidity $(1.68 \mathrm{~g} / \mathrm{L})$ were observed in comparison to the S. cerevisiae control [53].

The ratio of tartaric to malic acids will determine the acidity of the wine. Data regarding the influence of Metschnikowia on the final tartaric acid concentration are limited, though it seems to be slightly lower (up to 6\%) in co-inoculated fermentations [29]. Malic acid is susceptible to being consumed by some non-Saccharomyces wine-related species, with $M$. pulcherrima presenting the capacity to degrade it under single and sequential fermentation conditions by around $10 \%$ [28,42]. Nevertheless, in some cases, the malic acid content under sequential inoculation may increase [54].

If the same strain of $M$. pulcherrima is used along with two different strains of S. cerevisiae, a minimum increase in lactic and citric acid is observed, notwithstanding that they are not statistically significant [21]. That may confirm that lactic and citric acids seem to not be affected by M. pulcherrima $[26,27,29]$.

Recent studies have reported increases in fumaric acid for sequential fermentations between M. pulcherrima and S. cerevisiae, from $30 \%$ to $69 \%$ (up to $2.9 \mathrm{~g} / \mathrm{L}$ ). The same study reports increases in fumaric acid of up to $66 \%$, depending on the used M. pulcherrima strain [41].

\subsection{Volatile Acidity}

According to several works, the decrease in volatile acidity when M. pulcherrima is used varies between $10 \%$ and $75 \%[40,41,50]$, indicating that the reduction of volatile acidity in such conditions seems to be a trend. However, other studies have reported equal quantities of acetic acid when sequential fermentation was employed [21,26], or even an increase of around 20\% [29]. In vitro assays have shown that when synthetic must is used that different results are obtained when compared with natural white must. 


\subsection{Aroma Compounds}

\subsubsection{Fermentative Aromas}

Higher alcohols show the most irregular results of all the reported enological parameters for $M$. pulcherrima. Some studies show increments of up to $33 \%$ in the total concentration of higher alcohols for sequential fermentation involving $M$. pulcherrima compared to the $S$. cerevisiae controls $[27,28,53]$. However, other studies state the contrary effect, with reductions of around $30 \%[19,21,26,54]$. 2-phenylethanol is always described to increase about $30 \%$ when M. pulcherrima ferments in sequential fermentations $[29,47,53]$. Other compounds that increase under sequential fermentation are methionol [28], isoamyl alcohol [53], hexanol [47], and isobutanol [27]. On the other hand, those that generally decrease are 3-methyl-1-butanol [27], hexanol, and benzylic alcohol [26]. The discrepancy observed among the different studies is explained by the high variability observed in higher alcohols metabolism between $M$. pulcherrima strains, which is quantified to be about $29 \%$ (1-butanol), 66\% (2-phenylethanol), or 65\% (1-hexanol) depending on the studied higher alcohol [55].

M. pulcherrima usually increases the total concentration of esters $[40,47,53]$. Shikimic acid is a precursor for different esters such as benzaldehyde or ethyl cinnamate. The final concentration of shikimic acid decreases when M. pulcherrima ferments in mixed fermentations together with S. cerevisiae. Some studies observed a statically significant loss of shikimic acid corresponding to around $0.66 \%$. This fact could be related with the formation of aromatic compounds from shikimic acid, which could result in a more complex final product [29]. Among all ethyl esters, ethyl octanoate is the most relevant as its concentration increases around 14\% [29]. Acetates may decrease (around 30\% less) when no-Saccharomyces species ferment $[26,29,53]$.

The final total concentration of fatty acids generally increases from $0.52 \%$ to $7.5 \%$ when M. pulcherrima ferments [21,26,29]. Fatty acids such as octanoic or decanoic acids show great variability between studies. However, others such as hexanoic or pentanoic acid always increase when M. pulcherrima ferments [21,26,29].

Acetoin and diacetyl generally increase when using $M$. pulcherrima. Acetoin increases varied from 10 to $400 \%$, while diacetyl doubled when M. pulcherrima fermented [28].

Acetaldehyde usually decreases when non-Saccharomyces species ferment, improving the aromatic profile in wine [56]. Some studies report slight differences in acetaldehyde with no statistical significance $[19,21,28]$, while others report statistically significant decreases down to 40\% [26] for fermentations involving M. pulcherrima.

\subsubsection{Varietal Aromas}

Volatile sulfur molecules are important aroma compounds, including both pleasant and unpleasant aromas in wine. $\beta$-lyase is responsible for the main enzymatic activity involved in varietal thiols released from their S-conjugated nonvolatile precursors. Using non-Saccharomyces yeasts is a novel approach to enhancing the thiol profiles of wine [57]. Some M. pulcherrima strains present $\beta$-lyase activity [58]. M. viticola is the Metschnikowia species with higher $\beta$-lyase activity as $60 \%$ of the isolates show the enzymatic activity, while other Metschnikowia species show about 10\% [10].

One study reports thiols concentration (4 methyl-4-sulfanylpentan-2-one (4-MSP) and 3-sulfanylhexan-1-ol (3-SH)) to decrease when M. pulcherrima is used with S. cerevisiae in mixed fermentations [47]. On the contrary, another study [21] shows a M. pulcherrima strain in sequential inoculation with $S$. cerevisiae to increase 4-MSP concentration when compared with S. cerevisiae control. The thiol character (i.e., tropical, citrus aromas) of these wines increased as a decrease in the total concentration of higher alcohols, which overshadow the wine bouquet, accompanied thiol production. Most strains of Metschnikowia genus do not show sulfite reductase activity. This activity produces $\mathrm{H}_{2} \mathrm{~S}$ off-flavor $[10,59,60]$. A selected $M$. pulcherrima strain with high cystathionine- $\beta$-lyase activity released seven times more 4-methyl-4-sulfanylpentan-2-one (4-MSP) than the S. cerevisiae control. That strain did not influence the final concentration of acetylated 3-sulphanyl-hexanol (3-SHA) and 3-SH suffered 
a slight decrement [21]. Another study found traces of the methylated form of methanethiol (MeSH) in all fermentations involving M. pulcherrima [29].

Terpenes are the most important varietal aroma compounds in wine. The hydrolytic activity of glycosidase enzymes (mainly $\beta$-glucosidase, $\beta$-D-xylosidase, and $\alpha$-L-arabinofuranosidase) release terpenes from their glycosidic nonvolatile precursors. $\beta$-Glucosidase activity is not very common among M. pulcherrima isolates, being only present in around $25 \%$ of the strains [61]. A newer wide survey including different Metschnikowia species (M. viticola, M. pulcherrima, and M. fructicola) reported that most showed $\beta$-glucosidase, $\alpha$-L-arabinofuranosidase, and $\beta$-D-xylosidase activities [10]. The commercial strain of $M$. pulcherrima Flavia MP346 increases volatile terpene concentrations in wine because of its extracellular $\alpha$-L-arabinofuranosidase. One study reports $M$. fructicola to have a positive effect on terpene release during wine fermentation [23]. Although Metschnikowia $\beta$-glucosidase activity is effective at increasing the level of monoterpenols in wine, some environmental parameters, such as $\mathrm{pH}$, glucose, ethanol, and $\mathrm{SO}_{2}$, should be taken into consideration to optimize the release of these desirable aromatic compounds [62]. Contrarily, other works do not report any influence of M. pulcherrima on the total terpene concentration under wine fermentation conditions compared to $S$. cerevisiae single fermentation [26]. Several studies reported an increase in the total terpene concentration at the end of sequential fermentations involving M. pulcherrima compared to the single fermentation of S. cerevisiae up to $100 \%$. Linalool was the most affected by M. pulcherrima in the fermentative process $[29,47,53]$. Regarding $\beta$-damascenone, one study reported an increased concentration when M. pulcherrima fermented together with S. cerevisiae [46,47].

Other Metschnikowia species also positively influence wine aroma. A recent study tested the aromatic profile of wines inoculated with autochthonous strains of $S$. cerevisiae combined with M. fructicola. The results show that mixed fermentations with M. fructicola improved the aromatic complexity of wines, increasing the ester and terpene contents [23]. Using M. viticola in sequential fermentation with S. cerevisiae increased berry and fruity flavors in the produced wines [22]. The study compared M. viticola to other non-Saccharomyces species isolated in Denmark, such as Hanseniaspora uvarum in sequential fermentations with S. cerevisiae.

\subsection{Polysaccharides and Mannoproteins}

Some studies report most M. pulcherrima strains to release more polysaccharides than S. cerevisiae controls during single alcoholic fermentations with both species [19]. The M. pulcherrima strain that performed the best released $17 \%$ more polysaccharides than the best $S$. cerevisiae releaser. The same author observed a similar effect for mixed fermentations between M. pulcherrima and S. cerevisiae. The final polysaccharide concentration increased when the M. pulcherrima inoculum was higher. The increases varied from 20 to $50 \%$ depending on the M. pulcherrima initial inoculum proportion. Other study report M. pulcherrima to release higher amounts of mannoproteins than two S. cerevisiae controls in 50 and $90 \%$. Nevertheless, another S: cerevisiae strain released $37 \%$ more mannoproteins than the selected M. pulcherrima strain [52].

Ninety percentage of Metschnikowia species strains produce protease and pectinase [10]. However, in the case of M. pulcherrima some studies report not to be proteolytic [19], while other studies report all studied M. pulcherrima strains to possess this enzymatic activity [42]. Protease activity may solve protein haze formation in wines, being an alternative or a complement to the use of bentonite [63]. The role and expression of the protease MpApr1 produced by a M. pulcherrima strain have been studied [63,64]. Pectinase activity is strain-dependent on M. pulcherrima [65].

\subsection{Color, Anthocyanins, and Polyphenols}

Sequential fermentations involving M. pulcherrima and S. cerevisiae result in wines with a significant reduction in the final concentrations of grape anthocyanins such as delphinidin-3-O-glucoside $(44 \%)$, cyanidin-3-O-glucoside (39\%), petunidin-3-O-glucoside (16\%), peonidin-3-O-glucoside $(29 \%)$, and malvidin-3-O-glucoside (11\%) [27]. This phenomenon is explained because of a higher anthocyanin 
adsorption by the cell walls of the Metschnikowia species or because of the specific adsorption properties of the studied strain. This property is highly strain-dependent on other species such as S. cerevisiae [66]. Other studies report the final concentration of vitisins to be $17 \%$ lower than the S. cerevisiae control [27]. This is explained because of the lower acetaldehyde production of M. pulcherrima than the S. cerevisiae control of about $27 \%$ [26]. Vitisin B integrates acetaldehyde in its molecule and higher acetaldehyde concentrations produce higher levels in vitisin B [66]. M. pulcherrima is not a high producer of pyruvic acid. This explains the low formation of vitisin A in fermentations involving M. pulcherrima as pyruvic acid is part of Vitisin A molecule $[67,68]$. Fermentations involving $M$. pulcherrima show lower concentrations in acetylated anthocyanins such as vitisin A-(6"-acetylglucoside), petunidin-3-O-(6"-acetylglucoside), peonidin-3-O-(6"-acetylglucoside), and malvidin-3-O-(6"-acetylglucoside) by $30 \%, 10 \%, 5 \%$, and $10 \%$, respectively.

The opposite effect takes place for cumarilated anthocyanins, where fermentations involving M. pulcherrima show higher concentrations of petunidin-3-O-(6"-p-coumaroylglucoside) and malvidin-3-O-(6"-p-coumaroylglucoside) by $18 \%$ and $22 \%$, respectively. Fermentations involving $M$. pulcherrima co-inoculated with lactic bacteria showed higher final concentrations of $p$-coumaric acid than the S. cerevisiae controls by about 25\% [69]. Other non-Saccharomyces species also produce wines with higher $p$-coumaric acid contents [70-73]. This explains the higher concentrations of cumarilated anthocyanins. However, some authors recommend selecting strains that release moderate amounts of $p$-coumaric acid, as this compound can evolve into undesirable 4-ethylphenol if contamination by Brettanomyces/Dekkera genera takes place [74]. Fermentations involving M. pulcherrima show no presence of vinylphenol adducts such as malvidin-3-4-vinylguaiacol, malvidin-3-(600-acetylglucoside)-4-vinyphenol, or malvidin-3-(600-p-coumaroylglucoside)-4-vinylphenol. The S. cerevisiae control produced these highly stable color compounds. Other non-Saccharomyces species possess higher hydroxycinnamate decarboxylase activity than S. cerevisiae, which allows the production of higher concentrations of vinylphenol adducts [71,72]. No studies report this effect for M. pulcherrima. One study reported a final color intensity of about $20 \%$ lower than the S. cerevisiae control for fermentations involving M. pulcherrima. This effect took place due to the lower concentrations of most anthocyanins [27]. Nevertheless, co-inoculations of M. pulcherrima with lactic bacteria and S. cerevisiae showed higher concentrations in total phenolics and malvidin-3-O-glucoside than the combined S. cerevisiae and lactic acid bacteria control by about $8 \%$ and $20 \%$, respectively [69].

One study reports that co-fermentations with M. pulcherrima using Shiraz grapes reduced $10 \%$ of the tannin content compared to the S. cerevisiae controls [75]. Although these fermentations did not show differences in anthocyanin concentrations between treatments including M. pulcherrima and those performed with S. cerevisiae alone, fermentations involving $M$. pulcherrima showed higher color in about $6 \%$. Co-fermentations involving M. pulcherrima showed higher contents of nonbleachable pigments in about $10 \%$ [75].

M. pulcherrima possess polygalacturonase activity. This activity increases the concentration of anthocyanin and polyphenol compounds while decreasing wine turbidity [5].

\section{Sensory Influence in Wine}

There are multiple studies detailing the influence of the Metschnikowia species on the organoleptic properties of wines. A sensory evaluation of Muscat of Alexandria wines co-fermented with M. pulcherrima showed higher fruity and floral aromas in sequential fermentations than with the S. cerevisiae controls [53]. These results were supported, from a chemical point of view, by the higher observed concentrations of molecules such as terpenols, higher alcohols, and esters. One of the aromas that have been observed to be increased when M. pulcherrima is used is the "pear character", which is highly related to higher final contents in ethyl octanoate [24].

Wines obtained with sequential M. pulcherrima fermentation exhibit a higher overall impression than the S. cerevisiae controls due to the better aroma quality reported for such wines [26]. M. pulcherrima 
fermentations show a higher score in their fruity character, justified due to a lower final concentration of higher alcohols and a higher concentration of specific fruity esters such as ethyl hexanoate, ethyl octanoate, and ethyl decanoate. Additionally, fermentations involving M. pulcherrima showed lower oxidative perception, attributed to a lower concentration of ethanal. Fermentations involving M. pulcherrima showed a higher Riesling typicity and higher score in Riesling descriptors such as peach/apricot and especially in citrus/grape/fruit character. Further studies correlated higher scores in Verdejo typicity with higher concentrations in thiols in fermentations involving M. pulcherrima, especially for thiol 4-methyl-4-sulfanylpentan-2-one, whose content was 5 times higher than the S. cerevisiae control [21]. Those results justify the increase in Riesling typicity reported earlier [26], as some of the aroma sensory descriptors are related to thiol compounds [57].

Some studies report fermentations involving $M$. pulcherrima to show lower scores in sensory wine descriptors such as body, astringency, or bitterness than the S. cerevisiae controls [27]. The observed lower final tannin concentration justifies those results from a chemical point of view. A study regarding co-inoculated fermentations involving M. pulcherrima, S. cerevisiae, and lactic acid bacteria showed that panelists preferred this option to the control involving co-inoculation between S. cerevisiae and lactic acid bacteria [69]. In the study, fermentations involving M. pulcherrima scored lower in astringency and bitterness. However, other authors reported fermentations involving M. pulcherrima to show higher astringency than the S. cerevisiae control [75].

\section{Biocontrol Activity}

Some researchers have demonstrated that M. pulcherrima inhibits the development of Botrytis cinerea and other filamentous fungi, yeasts, and bacteria that are undesirable to the wine industry [16]. This inhibition takes place due to the chelation of iron, which inhibits the survival of other species [73]. M. pulcherrima also uses this strategy as a main tool for competition, due to the fact that iron is essential for fungal growth and pathogenesis [35]. This may negatively affect the fermentative process when mixed inoculums of S. cerevisiae and M. pulcherrima are used, due to the amensalism of M. pulcherrima to $S$. cerevisiae through iron depletion [49]. That ability has been successfully used in apple fruit trees for the biocontrol of B. cinerea [76]. Some authors [77] have demonstrated that in the culture media in which $M$. pulcherrima has been grown for 6 days, there is a $40 \%$ reduction in the grey mold McKinney index, and it was shown to be an effective biocontrol tool for controlling the postharvest decay of strawberries. A recent study characterized the genomic regulation of pulcherriminic acid, a pigment that exhibits strong antifungal activity against rhizospheric phytopathogenic fungi [78].

Due to the prohibition of some effective fungicides against $B$. cinerea and other undesirable fungi in the periods before harvesting, the use of biocontrol agents, such as M. pulcherrima, could be useful candidates for application in the winemaking industry. M. pulcherrima can not only be used for fungal inhibition, but also for the control and reduction of their toxic products, such as ochratoxin A (OTA). This yeast has the ability to reduce OTA by up to $80 \%$ at $30{ }^{\circ} \mathrm{C}$ after 15 days, with practically no adsorption to the yeast cell wall $[79,80]$.

M. fructicola, as well as M. pulcherrima, is used as biocontrol tool against filamentous fungi as well as against the spoilage of yeasts. The most important biocontrol molecule in M. fructicola is pulcherrimin; nevertheless, its biosynthesis has not yet been characterized [36]. The biocontrol activity of pulcherrimin has been demonstrated against B. cinerea, Alternaria alternata, and Penicillium expansum. Pulcherrimin is not the only antimicrobial defense mechanism, it also has been demonstrated that among the pull of different gene clusters involved in secondary metabolite production there are two genes involved in the synthesis of terpenes that can be potentially bioactive molecules against Penicillium digitatum [36]. 


\section{Main Selection Criteria for M. pulcherrima Strains}

The studies that compare fermentations involving different strains of M. pulcherrima species report a high strain variability for several wine quality parameters (Table 3). Because of this, some selection criteria should be established to improve the wine quality parameters reported in this review.

Table 3. Variability among different strains of M. pulcherrima strains for reported phenotypic responses to physicochemical fermentation parameters.

\begin{tabular}{cccc}
\hline Parameter & $\begin{array}{c}\text { Du Plessis et al., 2017 [42] } \\
\text { 7 strains of } \text { M. } \text { pulcherrima }\end{array}$ & $\begin{array}{c}\text { Escribano et al., 2018 [55] } \\
\text { 5 strains of } \text { M. } \text { pulcherrima }\end{array}$ & $\begin{array}{c}\text { Canonico et al., 2019 [20] } \\
\text { 7 strains of } \text { M. pulcherrima }\end{array}$ \\
\hline Residual sugar (g/L) & $2.63-0.00$ & $/$ & $/$ \\
Total acidity (g/L) & $3.94-3.63$ & $3.80-3.40$ & $/$ \\
pH & $3.70-3.51$ & $/$ & $4.04-3.50$ \\
Ethanol (\% v/v) & $9.58-8.10$ & $/$ & $/$ \\
Malic acid (g/L) & $1.91-1.50$ & $0.16-0.05$ & $0.37-0.26$ \\
Volatile acidity (g/L) & $0.37-0.21$ & $/$ & $/$ \\
Duration of AF (days) & $46-180$ & & \\
\hline
\end{tabular}

In our opinion, the first parameter to take into account in a M. pulcherrima selection process must be the absence of antagonism effects against $S$. cerevisiae as any positive effect over wine would have no sense if a proper alcoholic fermentation cannot take place. The main advantage about using M. pulcherrima is due to its positive influence on wine aroma. Regarding this fact, M. pulcherrima strains should be selected in order to release varietal aroma compounds, such as thiols and terpenes, while producing fruity esters such as ethyl octanoate. Fermentative power together with ethanol and sulfur dioxide resistance should be considered in order to allow the selected strains to perform longer during industrial alcoholic fermentations to make it easy to achieve the desired quality objectives. These parameters remain as the main limitation of the available commercial strains. Other secondary positive effects that could be selected are the ability to reduce the final ethanol content and to increase the glycerol concentration in final wines. Some parameters of additional interest are the anthocyanin absorption and polysaccharides release. Finally, some negative parameters reported for some M. pulcherrima strains such as diacetyl, acetoin, higher alcohols, or acetaldehyde must be avoided in the selected strains. Figure 3 summarizes the proposed M. pulcherrima selection parameters.

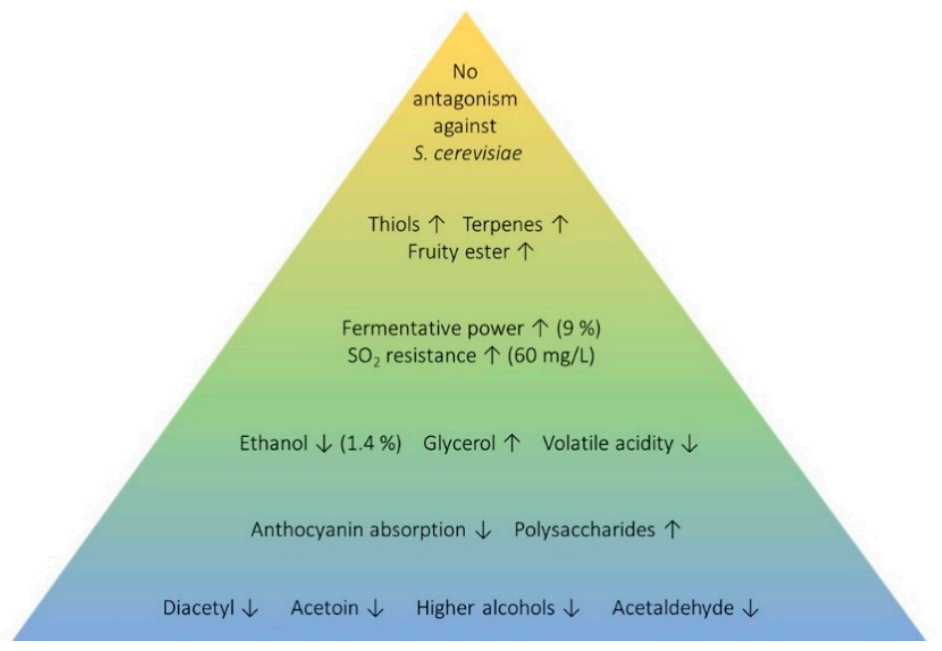

Figure 3. Summary of proposed Metschnikowia pulcherrima selection parameters.

\section{Conclusions}

M. pulcherrima has distinct characteristics that make this yeast useful in winemaking in comparison to other non-Saccharomyces species of enological interest. Nevertheless, the use of M. pulcherrima in enology is not a common option nowadays, but the range of potential applications of this species are 
vast. Some of the studied parameters are variable, depending on the used strain and the fermentation conditions. This is the reason why more studies should be carried out concerning the use of this yeast in enology. Other new Metschnikowia species, such as M. fruticola and M. viticola, are also beginning to be of interest for enology.

Author Contributions: J.V., J.R., I.B, I.B-V., D.M., F.C., A.S. and S.B. contributed to the scientific literature revision, text writing, and editing. Figures design: J.V. and I.B-V. All authors have read and agreed to the published version of the manuscript.

Funding: Funding was provided by Ossian Vides y Vinos S. L under the framework of project FPA1720300120 / IDI-20170703 (Centre for the Development of Industrial Technology (CDTI), Spain) and Bodegas Pago de Carraovejas under the framework of projects IDI-20180269 and IDI-20140448 (Centre for the Development of Industrial Technology (CDTI), Spain).

Acknowledgments: The authors acknowledge A. Acedo, from Biome Makers Inc, for sharing estimated figures about the occurrence and relative abundance of yeasts in different wine fermentation stages.

Conflicts of Interest: Ignacio Belda was an employee of Biome Makers (proprietor of WineSeq technology) when generating data contained in Figure 1B. The rest of the authors declare that there are no conflicts of interest.

\section{References}

1. Bordet, F.; Joran, A.; Klein, G.; Roullier-Gall, C.; Alexandre, H. Yeast-Yeast Interactions: Mechanisms, Methodologies and Impact on Composition. Microorganisms 2020, 8, 600. [CrossRef] [PubMed]

2. Castrillo, D.; Rabunal, E.; Neira, N.; Blanco, P. Oenological potential of non-Saccharomyces yeasts to mitigate effects of climate change in winemaking: Impact on aroma and sensory profiles of Treixadura wines. Fems. Yeast Res. 2019, 19, foz065. [CrossRef] [PubMed]

3. Lin, M.M.; Boss, P.K.; Walker, M.E.; Sumby, K.M.; Grbin, P.R.; Jiranek, V. Evaluation of indigenous non-Saccharomyces yeasts isolated from a South Australian vineyard for their potential as wine starter cultures. Int. J. Food Microbiol. 2020, 312, 108373. [CrossRef]

4. Esteves, M.; Barbosa, C.; Vasconcelos, I.; Tavares, M.J.; Mendes-Faia, A.; Mira, N.P.; Mendes-Ferreira, A. Characterizing the Potential of the Non-Conventional Yeast Saccharomycodes ludwigii UTAD17 in Winemaking. Microorganisms 2019, 7, 478. [CrossRef] [PubMed]

5. Belda, I.; Conchillo, L.B.; Ruiz, J.; Navascués, E.; Marquina, D.; Santos, A. Selection and use of pectinolytic yeasts for improving clarification and phenolic extraction in winemaking. Int. J. Food Microbiol. 2016, 223, 1-8. [CrossRef]

6. Spano, G.; Torriani, S. Editorial: Microbiota of Grapes: Positive and Negative Role on Wine Quality. Front. Microbiol. 2016, 7, 2036. [CrossRef]

7. Mendonca-Hagler, L.C.; Hagler, A.N.; Kurtzman, C.P. Phylogeny of Metschnikowia species estimated from partial rRNA sequences. Int. J. Syst. Bacteriol. 1993, 43, 368-373. [CrossRef]

8. Kurtzman, C.; Fell, J.W.; Boekhout, T. The Yeasts: A Taxonomic Study; Elsevier: Amsterdam, Netherlands, 2011; ISBN 97804444521491.

9. Brysch-Herzberg, M.; Seidel, M. Yeast diversity on grapes in two German wine growing regions. Int. J. Food Microbiol. 2015, 214, 137-144. [CrossRef]

10. Belda, I.; Ruiz, J.; Alastruey-Izquierdo, A.; Navascues, E.; Marquina, D.; Santos, A. Unraveling the Enzymatic Basis of Wine "Flavorome": A Phylo-Functional Study of Wine Related Yeast Species. Front. Microbiol. 2016, 7, 12. [CrossRef]

11. Gutiérrez López, C. Taxonomía de levaduras de origen enológico por espectrometría de masas; Universidad Complutense de Madrid: Madrid, Spain, 2017.

12. Grazia, A.; Pietrafesa, A.; Capece, A.; Pietrafesa, R.; Siesto, G.; Romano, P. Exploitation of technological variability among wild non-Saccharomyces yeasts to select mixed starters for the production of low alcohol wines. Proceedings of BIO Web of Conferences, 42nd World Congress of Vine and Wine, Geneva, Switzerland, 15-19 July 2019; p. 02031.

13. Morata, A.; Loira, I.; Escott, C.; del Fresno, J.M.; Bañuelos, M.A.; Suárez-Lepe, J.A. Applications of Metschnikowia pulcherrima in Wine Biotechnology. Fermentation 2019, 5, 63. [CrossRef] 
14. Zhang, B.Q.; Shen, J.Y.; Duan, C.Q.; Yan, G.L. Use of Indigenous Hanseniaspora vineae and Metschnikowia pulcherrima Co-fermentation With Saccharomyces cerevisiae to Improve the Aroma Diversity of Vidal Blanc Icewine. Front. Microbiol. 2018, 9, 2303. [CrossRef] [PubMed]

15. Roudil, L.; Russo, P.; Berbegal, C.; Albertin, W.; Spano, G.; Capozzi, V. Non-Saccharomyces commercial starter cultures: Scientific trends, recent patents and innovation in the wine sector. Recent Pat. Food Nutr. Agric. 2019, 10, 1-13. [CrossRef]

16. Sipiczki, M. Metschnikowia strains isolated from botrytized grapes antagonize fungal and bacterial growth by iron depletion. Appl. Env. Microbiol. 2006, 72, 6716-6724. [CrossRef]

17. Oro, L.; Ciani, M.; Comitini, F. Antimicrobial activity of Metschnikowia pulcherrima on wine yeasts. J. Appl. Microbiol. 2014, 116, 1209-1217. [CrossRef]

18. Tan, C.; Wang, L.; Xue, Y.; Lin, S.; Yu, G.; Yang, S. Purification and molecular characterization of a Metschnikowia saccharicola killer toxin lethal to a crab pathogenic yeast. FEMS Microbiol. Lett. 2018, 365, fny038. [CrossRef]

19. Comitini, F.; Gobbi, M.; Domizio, P.; Romani, C.; Lencioni, L.; Mannazzu, I.; Ciani, M. Selected non-Saccharomyces wine yeasts in controlled multistarter fermentations with Saccharomyces cerevisiae. Food Microbiol. 2011, 28, 873-882. [CrossRef]

20. Canonico, L.; Comitini, F.; Ciani, M. Metschnikowia pulcherrima selected strain for ethanol reduction in wine: Influence of cell immobilization and aeration condition. Foods 2019, 8, 378. [CrossRef] [PubMed]

21. Ruiz, J.; Belda, I.; Beisert, B.; Navascues, E.; Marquina, D.; Calderon, F.; Rauhut, D.; Santos, A.; Benito, S. Analytical impact of Metschnikowia pulcherrima in the volatile profile of Verdejo white wines. Appl. Microbiol. Biotechnol. 2018, 102, 8501-8509. [CrossRef]

22. Liu, J.; Arneborg, N.; Toldam-Andersen, T.B.; Petersen, M.A.; Bredie, W.L. Effect of sequential fermentations and grape cultivars on volatile compounds and sensory profiles of Danish wines. J. Sci. Food Agric. 2017, 97, 3594-3602. [CrossRef]

23. Boscaino, F.; Ionata, E.; La Cara, F.; Guerriero, S.; Marcolongo, L.; Sorrentino, A. Impact of Saccharomyces cerevisiae and Metschnikowia fructicola autochthonous mixed starter on Aglianico wine volatile compounds. J. Food Sci. Technol. 2019, 56, 4982-4991. [CrossRef]

24. Jolly, N.P.; Varela, C.; Pretorius, I.S. Not your ordinary yeast: Non-Saccharomyces yeasts in wine production uncovered. J. Fems. Yeast Res. 2014, 14, 215-237. [CrossRef] [PubMed]

25. González-Royo, E.; Pascual, O.; Kontoudakis, N.; Esteruelas, M.; Esteve-Zarzoso, B.; Mas, A.; Canals, J.M.; Zamora, F. Oenological consequences of sequential inoculation with non-Saccharomyces yeasts (Torulaspora delbrueckii or Metschnikowia pulcherrima) and Saccharomyces cerevisiae in base wine for sparkling wine production. Eur. Food Res. Technol. 2014, 240, 999-1012. [CrossRef]

26. Benito, S.; Hofmann, T.; Laier, M.; Lochbühler, B.; Schüttler, A.; Ebert, K.; Fritsch, S.; Röcker, J.; Rauhut, D. Effect on quality and composition of Riesling wines fermented by sequential inoculation with non-Saccharomyces and Saccharomyces cerevisiae. Eur. Food Res. Technol. 2015, 241, 707-717. [CrossRef]

27. Chen, K.; Escott, C.; Loira, I.; del Fresno, J.M.; Morata, A.; Tesfaye, W.; Calderon, F.; Suárez-Lepe, J.A.; Han, S.; Benito, S. Use of non-Sacharomyces yeasts and oenological tannin in red winemaking: Influence on colour, aroma and sensorial properties of young wines. Food Microbiol. 2018, 69, 51-63. [CrossRef]

28. Escribano-Viana, R.; Gonzalez-Arenzana, L.; Portu, J.; Garijo, P.; Lopez-Alfaro, I.; Lopez, R.; Santamaria, P.; Gutierrez, A.R. Wine aroma evolution throughout alcoholic fermentation sequentially inoculated with non-Saccharomyces/Saccharomyces yeasts. Food Res. Int. 2018, 112, 17-24. [CrossRef]

29. Dutraive, O.; Benito, S.; Fritsch, S.; Beisert, B.; Patz, C.-D.; Rauhut, D. Effect of Sequential Inoculation with Non-Saccharomyces and Saccharomyces Yeasts on Riesling Wine Chemical Composition. Fermentation 2019, 5, 79. [CrossRef]

30. Combina, M.; Elía, A.; Mercado, L.; Catania, C.; Ganga, A.; Martinez, C. Dynamics of indigenous yeast populations during spontaneous fermentation of wines from Mendoza, Argentina. Int. J. Food Microbiol. 2005, 99, 237-243. [CrossRef]

31. Lachance, M.A. Metschnikowia: Half tetrads, a regicide and the fountain of youth. Yeast 2016, 33, 563-574. [CrossRef]

32. Guzmán, B.; Lachance, M.-A.; Herrera, C.M. Phylogenetic analysis of the angiosperm-floricolous insect-yeast association: Have yeast and angiosperm lineages co-diversified? J. Mol. Phylogenetics Evol. 2013, 68, 161-175. [CrossRef] 
33. Sipiczki, M.; Horvath, E.; Pfliegler, W.P. Birth-and-Death Evolution and Reticulation of ITS Segments of Metschnikowia andauensis and Metschnikowia fructicola rDNA Repeats. Front. Microbiol. 2018, 9, 1193. [CrossRef]

34. Sipiczki, M.; Pfliegler, W.P.; Holb, I.J. Metschnikowia Species Share a Pool of Diverse rRNA Genes Differing in Regions That Determine Hairpin-Loop Structures and Evolve by Reticulation. PLoS ONE 2013, 8, e67384. [CrossRef] [PubMed]

35. Hershkovitz, V.; Sela, N.; Taha-Salaime, L.; Liu, J.; Rafael, G.; Kessler, C.; Aly, R.; Levy, M.; Wisniewski, M.; Droby, S. De-novo assembly and characterization of the transcriptome of Metschnikowia fructicola reveals differences in gene expression following interaction with Penicillium digitatum and grapefruit peel. BMC Genom. 2013, 14, 168. [CrossRef] [PubMed]

36. Piombo, E.; Sela, N.; Wisniewski, M.; Hoffmann, M.; Gullino, M.L.; Allard, M.W.; Levin, E.; Spadaro, D.; Droby, S. Genome sequence, assembly and characterization of two Metschnikowia fructicola strains used as biocontrol agents of postharvest diseases. Front. Microbiol. 2018, 9, 593. [CrossRef] [PubMed]

37. Venkatesh, A.; Murray, A.L.; Boyle, A.B.; Quinn Farrington, L.; Maher, T.J.; O'Gaora, P.; Wolfe, K.H.; O’Brien, C.E.; Butler, G. Draft genome sequence of a highly heterozygous yeast strain from the Metschnikowia pulcherrima Subclade, UCD127. Genome Announc. 2018, 6, e00550-00518. [CrossRef] [PubMed]

38. Hirao, A.S.; Imai, R.; Endoh, R.; Ohkuma, M.; Degawa, Y. Draft Genome Sequence of Novel Metschnikowia sp. Strain JCM 33374, a Nectar Yeast Isolated from a Bumblebee. Microbiol. Resour. Announc. 2019, 8, e00704-00719. [CrossRef] [PubMed]

39. Quiros, M.; Rojas, V.; Gonzalez, R.; Morales, P. Selection of non-Saccharomyces yeast strains for reducing alcohol levels in wine by sugar respiration. Int. J. Food Microbiol. 2014, 181, 85-91. [CrossRef]

40. Jolly, N.; Augustyn, O.; Pretorius, I. The effect of non-Saccharomyces yeasts on fermentation and wine quality. J. South Afr. J. Enol. 2003, 24, 55-62. [CrossRef]

41. Hranilovic, A.; Gambetta, J.M.; Jeffery, D.W.; Grbin, P.R.; Jiranek, V. Lower-alcohol wines produced by Metschnikowia pulcherrima and Saccharomyces cerevisiae co-fermentations: The effect of sequential inoculation timing. Int. J. Food Microbiol. 2020, 108651. [CrossRef]

42. Du Plessis, H.; Du Toit, M.; Hoff, J.; Hart, R.; Ndimba, B.; Jolly, N. Characterisation of non-Saccharomyces yeasts using different methodologies and evaluation of their compatibility with malolactic fermentation. $J$. South Afr. J. Enol. Vitic. 2017, 38, 46-63. [CrossRef]

43. Jolly, N.; Augustyn, O.; Pretorius, I. The use of Candida pulcherrima in combination with Saccharomyces cerevisiae for the production of Chenin blanc wine. J. South Afr. J. Enol. Vitic. 2003, 24, 63-69. [CrossRef]

44. Contreras, A.; Hidalgo, C.; Henschke, P.A.; Chambers, P.J.; Curtin, C.; Varela, C. Evaluation of non-Saccharomyces yeasts for the reduction of alcohol content in wine. Appl. Env. Microbiol. 2014, 80, 1670-1678. [CrossRef] [PubMed]

45. Zhu, X.; Navarro, Y.; Mas, A.; Torija, M.J.; Beltran, G. A Rapid Method for Selecting Non-Saccharomyces Strains with a Low Ethanol Yield. Microorganisms 2020, 0, 658. [CrossRef]

46. García, M.; Esteve-Zarzoso, B.; Cabellos, J.M.; Arroyo, T. Sequential Non-Saccharomyces and Saccharomyces cerevisiae Fermentations to Reduce the Alcohol Content in Wine. Fermentation 2020, 6, 60. [CrossRef]

47. Sadoudi, M.; Tourdot-Marechal, R.; Rousseaux, S.; Steyer, D.; Gallardo-Chacon, J.J.; Ballester, J.; Vichi, S.; Guerin-Schneider, R.; Caixach, J.; Alexandre, H. Yeast-yeast interactions revealed by aromatic profile analysis of Sauvignon Blanc wine fermented by single or co-culture of non-Saccharomyces and Saccharomyces yeasts. Food Microbiol. 2012, 32, 243-253. [CrossRef] [PubMed]

48. Laguna, L.; Bartolomé, B.; Moreno-Arribas, M.V. Mouthfeel perception of wine: Oral physiology, components and instrumental characterization. Trends Food Sci. Technol. 2017, 59, 49-59. [CrossRef]

49. Harlé, O.; Legrand, J.; Tesnière, C.; Pradal, M.; Mouret, J.-R.; Nidelet, T. Kinetic analysis of yeast-yeast interactions in oenological conditions. J. Biorxiv 2019, 363531.

50. Roca-Mesa, H.; Sendra, S.; Mas, A.; Beltran, G.; Torija, M.J. Nitrogen Preferences during Alcoholic Fermentation of Different Non-Saccharomyces Yeasts of Oenological Interest. Microorganisms 2020, 8, 157. [CrossRef]

51. Seguinot, P.; Ortiz-Julien, A.; Camarasa, C. Impact of Nutrient Availability on the Fermentation and Production of Aroma Compounds Under Sequential Inoculation With M. pulcherrima and S. cerevisiae. Front. Microbiol. 2020, 11, 305. [CrossRef] 
52. Belda, I.; Navascues, E.; Marquina, D.; Santos, A.; Calderon, F.; Benito, S. Outlining the influence of non-conventional yeasts in wine ageing over lees. Yeast 2016, 33, 329-338. [CrossRef]

53. Rodriguez, M.E.; Lopes, C.A.; Barbagelata, R.J.; Barda, N.B.; Caballero, A.C. Influence of Candida pulcherrima Patagonian strain on alcoholic fermentation behaviour and wine aroma. Int. J. Food Microbiol. 2010, 138, 19-25. [CrossRef]

54. Varela, C.; Sengler, F.; Solomon, M.; Curtin, C. Volatile flavour profile of reduced alcohol wines fermented with the non-conventional yeast species Metschnikowia pulcherrima and Saccharomyces uvarum. Food Chem. 2016, 209, 57-64. [CrossRef] [PubMed]

55. Escribano, R.; González-Arenzana, L.; Portu, J.; Garijo, P.; López-Alfaro, I.; López, R.; Santamaría, P.; Gutiérrez, A. Wine aromatic compound production and fermentative behaviour within different non-Saccharomyces species and clones. J. Appl. Microbiol. 2018, 124, 1521-1531. [CrossRef]

56. Han, G.; Webb, M.R.; Waterhouse, A.L. Acetaldehyde reactions during wine bottle storage. Food Chem. 2019, 290, 208-215. [CrossRef] [PubMed]

57. Ruiz, J.; Kiene, F.; Belda, I.; Fracassetti, D.; Marquina, D.; Navascues, E.; Calderon, F.; Benito, A.; Rauhut, D.; Santos, A.; et al. Effects on varietal aromas during wine making: A review of the impact of varietal aromas on the flavor of wine. Appl. Microbiol. Biotechnol. 2019, 103, 7425-7450. [CrossRef]

58. Zott, K.; Thibon, C.; Bely, M.; Lonvaud-Funel, A.; Dubourdieu, D.; Masneuf-Pomarede, I. The grape must non-Saccharomyces microbial community: Impact on volatile thiol release. Int. J. Food Microbiol. 2011, 151, 210-215. [CrossRef]

59. Barbosa, C.; Lage, P.; Esteves, M.; Chambel, L.; Mendes-Faia, A.; Mendes-Ferreira, A. Molecular and Phenotypic Characterization of Metschnikowia pulcherrima Strains from Douro Wine Region. Fermentation 2018, 4, 8. [CrossRef]

60. Mendoza, L.M.; Vega-Lopez, G.A.; Fernandez de Ullivarri, M.; Raya, R.R. Population and oenological characteristics of non-Saccharomyces yeasts associated with grapes of Northwestern Argentina. Arch Microbiol. 2019, 201, 235-244. [CrossRef] [PubMed]

61. Rodriguez, M.E.; Lopes, C.A.; van Broock, M.; Valles, S.; Ramon, D.; Caballero, A.C. Screening and typing of Patagonian wine yeasts for glycosidase activities. J. Appl. Microbiol. 2004, 96, 84-95. [CrossRef] [PubMed]

62. Rodríguez, M.E.; Lopes, C.; Valles, S.; Giraudo, M.R.; Caballero, A. Selection and preliminary characterization of $\beta$-glycosidases producer Patagonian wild yeasts. Enzym. Microb. Technol. 2007, 41, 812-820. [CrossRef]

63. Marangon, M.; Van Sluyter, S.C.; Robinson, E.M.; Muhlack, R.A.; Holt, H.E.; Haynes, P.A.; Godden, P.W.; Smith, P.A.; Waters, E.J. Degradation of white wine haze proteins by Aspergillopepsin I and II during juice flash pasteurization. Food Chem. 2012, 135, 1157-1165. [CrossRef]

64. Snyman, C.; Theron, L.W.; Divol, B. The expression, secretion and activity of the aspartic protease MpAPr1 in Metschnikowia pulcherrima IWBT Y1123. J. Ind. Microbiol. Biotechnol. 2019, 46, 1733-1743. [CrossRef] [PubMed]

65. Hong, M.; Li, J.; Chen, Y. Characterization of tolerance and multi-enzyme activities in non-Saccharomyces yeasts isolated from Vidal blanc icewine fermentation. J. Food Biochem. 2019, 43, e13027. [CrossRef] [PubMed]

66. Benito, A.; Calderon, F.; Benito, S. Combined Use of S. pombe and L. thermotolerans in Winemaking. Beneficial Effects Determined Through the Study of Wines' Analytical Characteristics. Molecules 2016, 21, 1744. [CrossRef] [PubMed]

67. Benito, S. Combined Use of Lachancea thermotolerans and Schizosaccharomyces pombe in Winemaking: A Review. Microorganisms 2020, 8, 655. [CrossRef]

68. Benito, Á.; Calderón, F.; Benito, S. The Influence of Non-Saccharomyces Species on Wine Fermentation Quality Parameters. Fermentation 2019, 5, 54. [CrossRef]

69. Minnaar, P.P.; du Plessis, H.W.; Jolly, N.P.; van der Rijst, M.; du Toit, M. Non-Saccharomyces yeast and lactic acid bacteria in Co-inoculated fermentations with two Saccharomyces cerevisiae yeast strains: A strategy to improve the phenolic content of Syrah wine. Food Chem. X 2019, 4, 100070. [CrossRef]

70. Ngqumba, Z.; Ntushelo, N.; Jolly, N.P.; Ximba, B.J.; Minnaar, P.P. Effect of Torulaspora delbrueckii Yeast Treatment on Flavanols and Phenolic Acids of Chenin blanc Wines. South Afr. J. Enol. Vitic. 2017, 38, 192-200. [CrossRef]

71. Benito, Á.; Calderón, F.; Benito, S. The combined use of Schizosaccharomyces pombe and Lachancea thermotolerans —effect on the anthocyanin wine composition. Molecules 2017, 22, 739. [CrossRef] 
72. Benito, S. The impacts of Schizosaccharomyces on winemaking. Appl. Microbiol. Biotechnol. 2019, 103, 4291-4312. [CrossRef]

73. Benito, S. The impacts of Lachancea thermotolerans yeast strains on winemaking. Appl. Microbiol. Biotechnol. 2018, 102, 6775-6790. [CrossRef]

74. Benito, S.; Palomero, F.; Morata, A.; Calderon, F.; Suarez-Lepe, J.A. A method for estimating Dekkera/Brettanomyces populations in wines. J. Appl. Microbiol. 2009, 106, 1743-1751. [CrossRef]

75. Hranilovic, A.; Li, S.; Boss, P.K.; Bindon, K.; Ristic, R.; Grbin, P.R.; Van der Westhuizen, T.; Jiranek, V. Chemical and sensory profiling of Shiraz wines co-fermented with commercial non-Saccharomyces inocula. Aust. J. Grape Wine Res. 2018, 24, 166-180. [CrossRef]

76. Saravanakumar, D.; Ciavorella, A.; Spadaro, D.; Garibaldi, A.; Gullino, M.L. Metschnikowia pulcherrima strain MACH1 outcompetes Botrytis cinerea, Alternaria alternata and Penicillium expansum in apples through iron depletion. Postharvest Biol. Technol. 2008, 49, 121-128. [CrossRef]

77. Oro, L.; Feliziani, E.; Ciani, M.; Romanazzi, G.; Comitini, F. Volatile organic compounds from Wickerhamomyces anomalus, Metschnikowia pulcherrima and Saccharomyces cerevisiae inhibit growth of decay causing fungi and control postharvest diseases of strawberries. Int. J. Food Microbiol. 2018, 265, 18-22. [CrossRef] [PubMed]

78. Gore-Lloyd, D.; Sumann, I.; Brachmann, A.O.; Schneeberger, K.; Ortiz-Merino, R.A.; Moreno-Beltran, M.; Schlafli, M.; Kirner, P.; Santos Kron, A.; Rueda-Mejia, M.P.; et al. Snf2 controls pulcherriminic acid biosynthesis and antifungal activity of the biocontrol yeast Metschnikowia pulcherrima. Mol. Microbiol. 2019, 112, 317-332. [CrossRef]

79. Spadaro, D.; Garibaldi, A. Containment of Mycotoxins in the Food Chain by Using Decontamination and Detoxification Techniques. In Practical Tools for Plant and Food Biosecurity; Gullino, M.L., Stack, J., Fletcher, J., Mumford, J., Eds.; Springer: Dordrecht, The Netherlands, 2017; pp. 163-177. [CrossRef]

80. Benito, S. The Management of Compounds that Influence Human Health in Modern Winemaking from an HACCP Point of View. Fermentation 2019, 5, 33. [CrossRef] 